\title{
Epigenome-wide association study in hepatocellular carcinoma: Identification of stochastic epigenetic mutations through an innovative statistical approach
}

\author{
Davide Gentilini ${ }^{1}$, Stefania Scala ${ }^{2}$, Germano Gaudenzi ${ }^{3}$, Paolo Garagnani, ${ }^{4,5}$, Miriam \\ Capri $^{4,5}$, Matteo Cescon ${ }^{6}$, Gian Luca Grazi ${ }^{7}$, Maria Giulia Bacalini ${ }^{8}$, Serena Pisoni ${ }^{1}$, \\ Alessandra Dicitore ${ }^{1}$, Luisa Circelli9 ${ }^{9}$ Sara Santagata ${ }^{2}$, Francesco Izzo $^{10}$, Anna \\ Maria Di Blasio ${ }^{1}$, Luca Persani ${ }^{1,3}$, Claudio Franceschi ${ }^{4,5,8}$ and Giovanni Vitale ${ }^{1,3}$ \\ ${ }^{1}$ Istituto Auxologico Italiano IRCCS, Cusano Milanino, Milan, Italy \\ ${ }^{2}$ Functional Genomics, Istituto Nazionale per lo Studio e la Cura dei Tumori, IRCCS Fondazione "G. Pascale", Napoli, Italy \\ ${ }^{3}$ Department of Clinical Sciences and Community Health (DISCCO), University of Milan, Milan, Italy \\ ${ }^{4}$ Department of Experimental, Diagnostic and Specialty Medicine, Alma Mater Studiorum, University of Bologna, Bologna, Italy \\ ${ }^{5}$ Interdepartmental Center "L. Galvani", University of Bologna, Bologna, Italy \\ ${ }^{6}$ DIMEC-Department of General Surgery and Medicine Sciences, S. Orsola-Malpighi Hospital, Bologna, Italy. \\ ${ }^{7}$ Regina Elena National Cancer Institute Via Elio Chianesi 53, Rome, Italy \\ ${ }^{8}$ IRCCS Institute of Neurological Sciences, Bologna, Italy \\ ${ }^{9}$ Department of Experimental Oncology, Laboratory of Molecular Biology and Viral Oncology, Istituto Nazionale per lo Studio \\ e la Cura dei Tumori, Fondazione "G. Pascale", Napoli, Italy \\ ${ }^{10}$ Department of Surgical Oncology, Abdominal and Hepatobiliary Unit, Istituto Nazionale per lo Studio e la Cura dei Tumori, \\ IRCCS Fondazione " G. Pascale", Napoli, Italy
}

Correspondence to: Giovanni Vitale, email: giovanni.vitale@unimi.it

Keywords: hepatocellular carcinoma, stochastic epigenetic mutation, epigenetics, DNA methylation, genome-wide

Received: January 27, $2017 \quad$ Accepted: April 15, $2017 \quad$ Published: April 27, 2017

Copyright: Gentilini et al. This is an open-access article distributed under the terms of the Creative Commons Attribution License 3.0 (CC BY

3.0), which permits unrestricted use, distribution, and reproduction in any medium, provided the original author and source are credited.

\section{ABSTRACT}

Hepatocellular carcinoma (HCC) results from accumulation of both genetic and epigenetic alterations. We investigated the genome-wide DNA methylation profile in 69 pairs of HCC and adjacent non-cancerous liver tissues using the Infinium HumanMethylation 450K BeadChip array. An innovative analytical approach has been adopted to identify Stochastic Epigenetic Mutations (SEMs) in HCC.

HCC and peritumoral tissues showed a different epigenetic profile, mainly characterized by loss of DNA methylation in HCC. Total number of SEMs was significantly higher in HCC tumor (median: 77,370) than in peritumoral (median: $5,656)$ tissues and correlated with tumor grade. A significant positive association emerged between SEMs measured in peritumoral tissue and hepatitis B and/or C virus infection status. A restricted number of SEMs resulted to be shared by more than $90 \%$ of HCC tumor samples and never present in peritumoral tissue. This analysis allowed the identification of four epigenetically regulated candidate genes (AJAP1, ADARB2, PTPRN2, SDK1), potentially involved in the pathogenesis of HCC.

In conclusion, HCC showed a methylation profile completely deregulated and very far from adjacent non-cancerous liver tissues. The SEM analysis provided valuable clues for further investigations in understanding the process of tumorigenesis in HCC.

\section{INTRODUCTION}

Hepatocellular carcinoma (HCC) is a common cancers and the second leading cause of cancer-related death among males in the world [1]. Indeed, advanced
HCC not eligible for local therapies has limited chances of cure [2], notwithstanding a massive effort in identifying novel therapeutic targets and predictive markers [3-5]. The pathogenesis of HCC is multifactorial and includes several extrinsic and intrinsic factors. Chronic liver 
damage secondary to viral hepatitis, alcohol abuse or non-alcoholic steatohepatitis, represents the most critical determinant in the development of this tumor. Several recent studies have provided relevant insights in this field through the characterization of HCC by using whole genome/exome sequencing, genome-wide methylation arrays and RNA sequencing [6-8]. Although it is known that $\mathrm{HCC}$ results from accumulation of both genetic and epigenetic alterations, the molecular pathogenesis of this tumor is still not completely understood. Indeed, HCC is a complex and heterogeneous disease [9].

DNA methylation is one of the most widely characterized epigenetic modifications implicated in cancer development. Several studies evaluated the DNA methylation profile in HCC through genome-wide arrays [10-14]. Most of these reports compared the mean methylation level calculated for each $\mathrm{CpG}$ site in human HCC with that in adjacent non-cancerous liver tissue, and correlated the tumor methylation profile with clinical and pathological parameters in order to obtain a deeper understanding of the pathogenesis of this tumor. While this approach allows to identify epigenetic alterations shared by a group of subjects and potentially associated with their phenotype, rare or stochastic epigenetic alterations, that are not shared among subjects and minimally affect the mean methylation level of the group, remain unexplored, although they may play a role in hepatocarcinogenesis. In addition, an analytical strategy based on comparisons of mean methylation values does not allow to process data obtained from a single subject [15].

Epigenetic mutations, or the more common term "epimutations" are heritable changes in gene activity not associated with a DNA mutation but rather with gain or loss of DNA methylation or other inheritable modifications of chromatin [16]. We have recently developed an analytical approach able to identify stochastic epigenetic mutations (SEMs) not shared among subjects. We applied this peculiar analytical strategy to investigate the relations between stochastic epigenetic alterations and aging [15].

In the present study, we investigated the genome-wide DNA methylation profile in $\mathrm{HCC}$, adjacent non-cancerous liver tissue and normal liver tissue. A new analytical approach has been adopted to identify epimutations potentially involved in the development of HCC.

\section{RESULTS}

\section{Clinical and pathological characteristics of HCC patients}

Clinical and pathological characteristics of enrolled HCC patients are described in Table 1 . The mean age at HCC diagnosis was $65.9 \pm 8.8$ years. Most patients were male $(76.8 \%)$ and positive for $\mathrm{HCV}(59.5 \%)$. Among the $69 \mathrm{HCC}$ patients, $87 \%$ have pathologically defined cirrhosis and $85.6 \%$ have tumors grade II.

The complexity of variability of all the phenotypic traits has been reduced using Multiple Factor Analysis (Supplementary Figure 1). The first and second dimensions explained $18.29 \%$ and $16.63 \%$, respectively, of the total variability of phenotypic traits.

\section{Genome-wide methylation profiles in HCC tumor and adjacent non-cancerous tissues}

A dimension reduction approach was used to visually inspect the dataset for signals in the methylation values. The Multi Dimensional Scaling Analysis was performed considering methylation signals from all $\mathrm{CpG}$ sites (Figure 1A) and in several genomic regions (tiling, genes, promoters and $\mathrm{CpG}$ Islands) (Figure 1B). This analysis showed a dramatic difference in methylation levels between HCC and peritumoral tissues. The Figure 2 shows hierarchical clustering of samples based on the top 1,000 CpG loci differentially methylated between HCC tumor and adjacent tissues. Excellent separation of tumor and peritumoral non-cancerous tissues was observed with only 3 misclassifications.

Paired differential methylation analysis between HCC vs peritumoral tissues was computed across the entire epigenome and selecting specific regions. The overall analysis identified 302,133 CpG sites out of 473,929 across the entire epigenome that significantly differed in methylation levels. Among all significant $\mathrm{CpG}$ sites, 36,615 probes resulted to have a delta greater than $|0.30|$. Differential methylation at the region level was computed based on a variety of metrix and combining methylation values inside tiling, genes, promoters and $\mathrm{CpG}$ Islands. Considering all the subgroups, the number of regions that resulted significantly different between the two sets and the number of the regions included in the array were: 105,827 and 131,743 for tiling, respectively; 25,572 and 29,592 for genes, respectively; 22,827 and 29,740 for promoters, respectively; 17,534 and 25,837 for CpG islands, respectively. Mean DNA methylation differences are represented as a volcano plot in Figure 3. Scatterplots for differential methylation at site and regional levels are shown in Supplementary Figure 2.

These data indicate that aberrant DNA methylation in HCC is a very common event, covering the entire epigenome and mainly characterized by a loss of methylation in the tumor tissue. Considering that methylation differences between the two groups resulted extremely strong and involved the whole epigenome, a prioritization of significant results has been performed. The top 10 hypomethylated or hypermethylated genes extracted from this analysis and ranked by statistical significance are reported in Table 2. 


\begin{tabular}{|c|c|}
\hline Variables & Number of cases (\%) \\
\hline \multicolumn{2}{|l|}{$\overline{\text { Age }}$} \\
\hline$<60$ years & $17(24.6)$ \\
\hline$>60$ years & $52(75.4)$ \\
\hline \multicolumn{2}{|l|}{ Gender } \\
\hline Male & $53(76.8)$ \\
\hline Female & $16(23.2)$ \\
\hline \multicolumn{2}{|l|}{ Viral infection } \\
\hline No Viral Infection & $15(21.8)$ \\
\hline $\mathrm{HBV}$ & $9(13)$ \\
\hline $\mathrm{HCV}$ & $41(59.5)$ \\
\hline $\mathrm{HBV}$ and $\mathrm{HCV}$ & $4(5.7)$ \\
\hline \multicolumn{2}{|l|}{ Alcoholic liver disease } \\
\hline Yes & $3(4.4)$ \\
\hline No & $66(95.6)$ \\
\hline \multicolumn{2}{|l|}{ Non-alcoholic steatohepatitis } \\
\hline Yes & $8(11.5)$ \\
\hline No & $61(88.5)$ \\
\hline \multicolumn{2}{|l|}{ Cirrhosis } \\
\hline Yes & $60(87)$ \\
\hline No & $9(13)$ \\
\hline \multicolumn{2}{|l|}{ Child-Pugh class } \\
\hline A & $57(82.6)$ \\
\hline B & $12(17.4)$ \\
\hline \multicolumn{2}{|l|}{ Tumor Grade } \\
\hline I & $3(4.2)$ \\
\hline II & $59(85.6)$ \\
\hline III & $7(10.2)$ \\
\hline \multicolumn{2}{|l|}{ Tumor Number } \\
\hline 1 & $49(71)$ \\
\hline 2 & $11(15.9)$ \\
\hline 3 & $4(5.7)$ \\
\hline 4 & $5(7.4)$ \\
\hline
\end{tabular}

\section{Stochastic epigenetic mutation analysis}

For each sample, as described in the Material and Method section, the total number of SEMs was calculated using tissue from normal liver as reference. The number of SEMs resulted to be statistically significant higher in HCC (median: 77,370, IQR: 58,260-92,220) compared to adjacent non-cancerous tissue (median: 5,656, IQR: $2,068-7,431, p=1.8 \times 10^{-11}$ ) and normal liver tissue extracted from healthy subjects (median: 1,308 , IQR: $854-2,148, p=2 \times 10^{-16}$ ) (Figure 4). Chromosomal distribution of SEMs in HCC samples and adjacent non- cancerous tissue has been reported in Supplementary Figure 3.

\section{Associations between SEMs and clinical and pathological characteristics}

A multivariate regression analysis was performed in order to identify clinical and pathological traits potentially associated with SEMs. The number of SEMs identified in HCC and adjacent non-tumor tissue has been used as dependent variable, while specific phenotypic traits (viral infections, alcoholic liver disease, non-alcoholic 
Table 2: Top 10 ranked hypomethylated or hypermethylated genes in HCC tumor tissue obtained after prioritization of all differentially methylated probes

\section{Hypomethylated genes}

\begin{tabular}{|c|c|c|c|c|c|c|c|c|c|}
\hline \multirow[b]{2}{*}{ Gene Symbol } & \multirow[b]{2}{*}{ Ensemble_ID } & \multirow[b]{2}{*}{ Chromosome } & \multirow[b]{2}{*}{ Start } & \multicolumn{6}{|c|}{$\begin{array}{c}\text { Mean Methylation } \\
\text { values }\end{array}$} \\
\hline & & & & End & $\begin{array}{l}\text { Number of } \\
\text { CpG sites }\end{array}$ & $\begin{array}{l}\text { Peritumoral } \\
\text { Tissue }\end{array}$ & $\begin{array}{l}\text { Tumor } \\
\text { Tissue }\end{array}$ & Delta & Adjusted $P$ Value \\
\hline IGF1R & ENSG00000140443 & $\operatorname{chr} 15$ & 99192200 & 99507759 & 129 & 0.698 & 0.449 & 0.24 & 1.39E-22 \\
\hline HGF & ENSG00000019991 & $\operatorname{chr} 7$ & 81328322 & 81399754 & 9 & 0.433 & 0.237 & 0.19 & $1.66815 \mathrm{E}-17$ \\
\hline HLA-DQA1 & ENSG00000196735 & chr6 & 32595956 & 32614839 & 8 & 0.583 & 0.341 & 0.24 & $1.49596 \mathrm{E}-19$ \\
\hline PIK3CG & ENSG00000105851 & $\operatorname{chr} 7$ & 106505723 & 106547590 & 12 & 0.736 & 0.473 & 0.26 & $2.92839 \mathrm{E}-19$ \\
\hline MAPK10 & ENSG00000109339 & $\operatorname{chr} 4$ & 86936276 & 87515284 & 40 & 0.638 & 0.449 & 0.18 & $1.14679 \mathrm{E}-19$ \\
\hline KDR & ENSG00000128052 & chr4 & 55944644 & 55991756 & 9 & 0.392 & 0.270 & 0.12 & 5.39177E-13 \\
\hline FGFR1 & ENSG00000077782 & chr8 & 38268656 & 38326352 & 29 & 0.407 & 0.365 & 0.04 & $2.63192 \mathrm{E}-12$ \\
\hline GNGT2 & ENSG00000167083 & chr17 & 47280153 & 47287936 & 11 & 0.587 & 0.388 & 0.19 & $3.49546 \mathrm{E}-17$ \\
\hline PLCB4 & ENSG00000101333 & chr20 & 9049410 & 9461889 & 8 & 0.618 & 0.355 & 0.26 & 6.88013E-21 \\
\hline ADCY2 & ENSG00000078295 & chr5 & 7396321 & 7830194 & 29 & 0.667 & 0.363 & 0.30 & $9.6768 \mathrm{E}-27$ \\
\hline
\end{tabular}

\section{Hypermethylated genes}

\begin{tabular}{|c|c|c|c|c|c|c|c|c|c|}
\hline \multirow[b]{2}{*}{ Gene Symbol } & \multirow[b]{2}{*}{ Ensemble_ID } & \multirow[b]{2}{*}{ Chromosome } & \multirow[b]{2}{*}{ Start } & \multirow[b]{2}{*}{ End } & \multicolumn{3}{|c|}{ Mean Methylation values } & \multirow[b]{2}{*}{ Delta } & \multirow[b]{2}{*}{$\begin{array}{l}\text { Adjusted } \\
P \text { Value }\end{array}$} \\
\hline & & & & & $\begin{array}{l}\text { Number of } \\
\text { CpG sites }\end{array}$ & $\begin{array}{l}\text { Peritumoral } \\
\text { Tissue }\end{array}$ & $\begin{array}{l}\text { Tumor } \\
\text { Tissue }\end{array}$ & & \\
\hline APC & ENSG00000134982 & $\operatorname{chr} 5$ & 112043195 & 112181936 & 25 & 0.307 & 0.596 & -0.28 & $1.76369 \mathrm{E}-20$ \\
\hline HIST1H4F & ENSG00000198327 & chr6 & 26240561 & 26240976 & 4 & 0.140 & 0.482 & -0.34 & $1.50784 \mathrm{E}-24$ \\
\hline FGF19 & ENSG00000162344 & chr11 & 69513000 & 69519410 & 19 & 0.194 & 0.434 & -0.23 & $5.56857 \mathrm{E}-18$ \\
\hline FZD1 & ENSG00000157240 & chr7 & 90893783 & 90898123 & 9 & 0.321 & 0.557 & -0.23 & $7.55218 \mathrm{E}-26$ \\
\hline LPAR2 & ENSG00000064547 & $\operatorname{chr} 19$ & 19734477 & 19739739 & 16 & 0.375 & 0.570 & -0.19 & $3.69839 \mathrm{E}-17$ \\
\hline HIST1H3F & ENSG00000256316 & chr6 & 26250370 & 26250835 & 4 & 0.101 & 0.442 & -0.34 & $3.81087 \mathrm{E}-26$ \\
\hline HIST1H3G & ENSG00000256018 & chr6 & 26271146 & 26271612 & 5 & 0.324 & 0.582 & -0.25 & $9.95446 \mathrm{E}-23$ \\
\hline HIST1H3J & ENSG00000197153 & chr6 & 27858093 & 27860884 & 7 & 0.263 & 0.534 & -0.27 & $1.27291 \mathrm{E}-18$ \\
\hline PMAIP1 & ENSG00000141682 & $\operatorname{chr} 18$ & 57567180 & 57571538 & 2 & 0.059 & 0.27 & -0.22 & $3.79856 \mathrm{E}-16$ \\
\hline RASGRF2 & ENSG00000113319 & $\operatorname{chr} 5$ & 80256491 & 80525975 & 30 & 0.696 & 0.712 & -0.02 & $9.64807 \mathrm{E}-08$ \\
\hline
\end{tabular}

steatohepatitis, cirrhosis, Child-Pugh class, tumor grade, tumor number and Multiple Factor Analysis dimensions) have been adopted as independent variables. All the multiple regression models have been adjusted for age.

Viral infection resulted significantly associated to the number of SEMs observed in peritumoral tissue. In the multivariate regression hepatitis $\mathrm{B}$ virus (HBV), hepatitis $\mathrm{C}$ virus (HCV) and $\mathrm{HBV}+\mathrm{HCV}$ infection status resulted independently associated to the number of SEMs observed in peritumoral tissue ( $p=8 \times 10^{-5}, p=0.002$ and $p=0.027$, respectively) and, less pronounced, in tumor $(p=0.032$, $p=0.034$ and $p=0.075$, respectively). Figure 5 shows the number of SEMs observed in peritumoral tissue (Figure 5A) and in HCC tumor tissue (Figure 5B) according to the viral infection status.
Tumor grade resulted significantly associated to the number of SEMs observed in HCC tumor tissue ( $p$ $=0.02)$, but not in peritumoral tissue $(\mathrm{p}=0.40)$. Figure 6 shows the number of SEMs observed in peritumoral tissue (Figure 6A) and in HCC tumor tissue (Figure 6B) according to the tumor grade.

Complexity of clinical traits has been initially reduced using the Multiple Factor Analysis. The correlogram in Supplementary Figure 1 shows clinical traits associated to each dimension. The multiple regression analysis indicated that dimensions 1 ( $p=$ $\left.2 \times 10^{-7}\right)$ and $5\left(p=1.6 \times 10^{-5}\right)$ resulted associated to SEMs observed in HCC tumor, while only dimension 3 (mainly collecting variability of age, $\mathrm{HBV}, \mathrm{HBV}+\mathrm{HCV}$ and non-alcoholic steatohepatitis) resulted significantly associated to the number of SEMs observed in HCC 
A

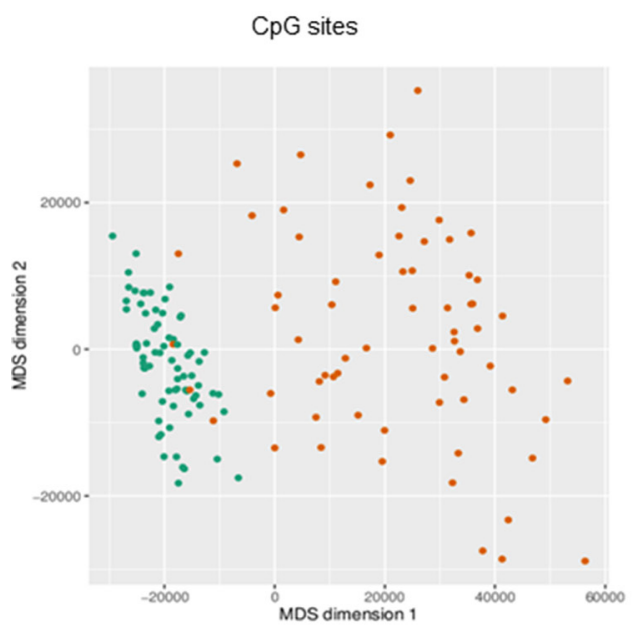

B

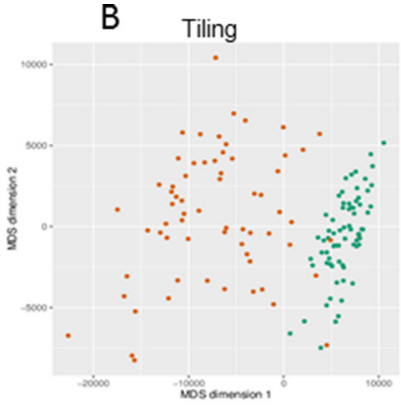

Promoters
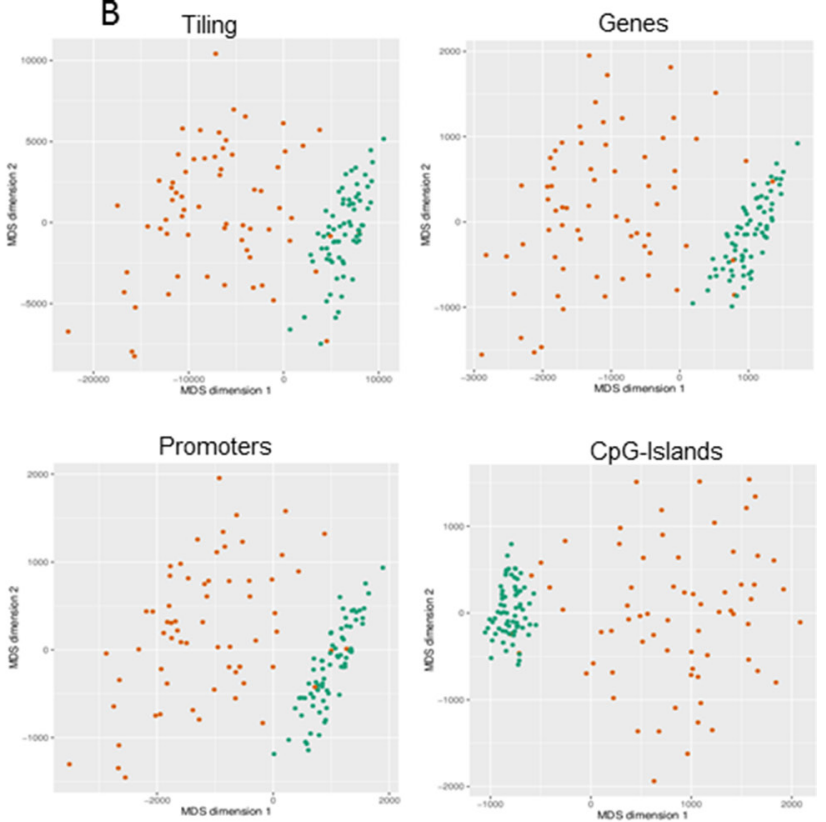

Peritumoral Tissue

Tumoral Tissue

Figure 1: Exploratory analysis of methylation data. Dimension reduction obtained by Multi Dimensional Scaling (MDS) is used to visually resume the complexity of methylation profile in HCC and peritumoral tissues at site level (A) and at regional level (B). Plots have been obtained using the first two dimensions.
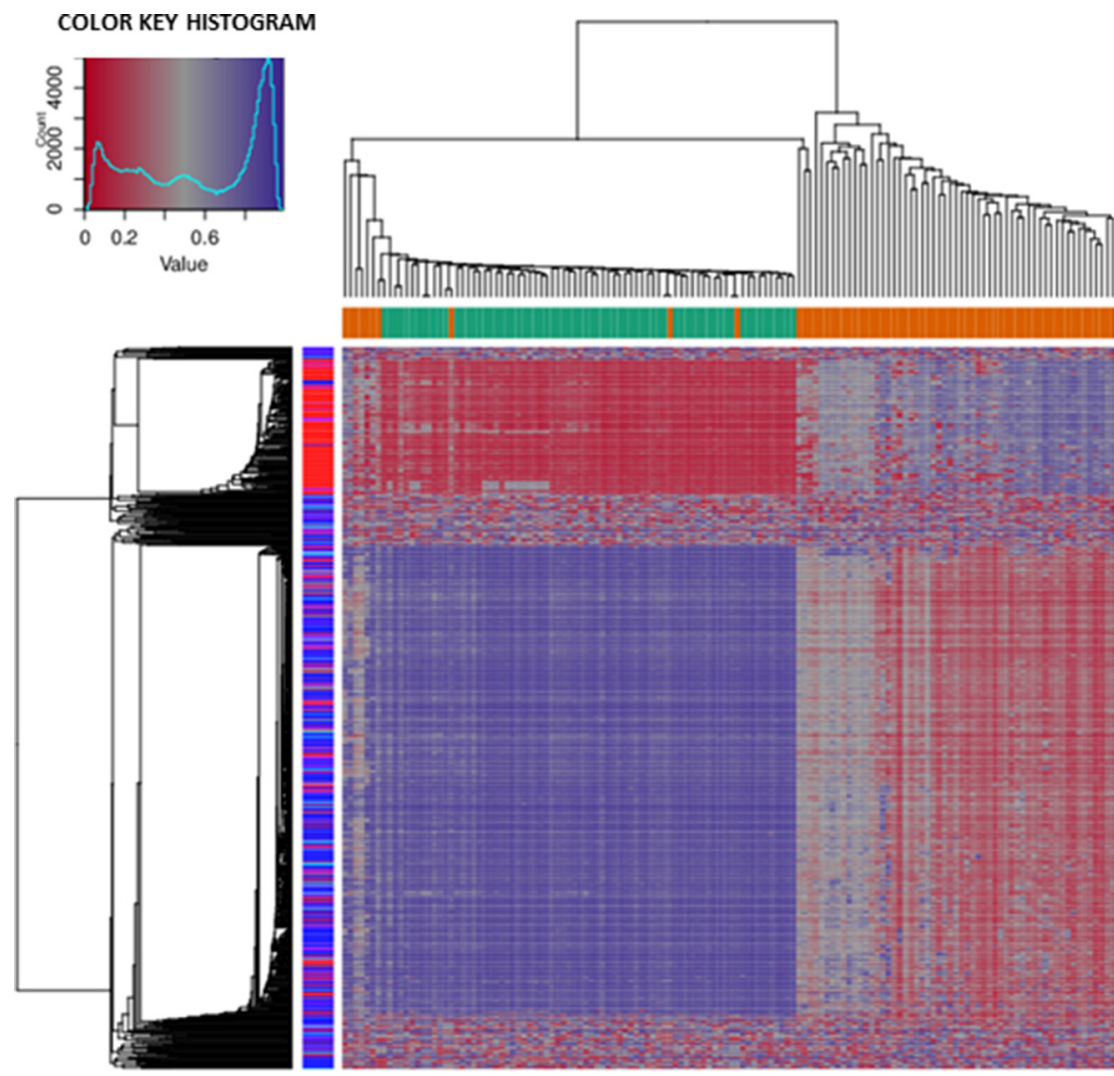

Peritumoral Tissue

Tumoral Tissue

Figure 2: Hierarchical cluster analysis. Hierarchical cluster analysis of the top 1000 significantly differentially methylated cpG sites between 69 pairs of HCC and adjacent non-cancerous liver tissues. 
tumor and peritumoral tissues $(p=0.0003$ and $p=0.015$, respectively).

For other phenotypic traits the associations with the number of SEMs were not significant.

\section{SEMs annotation analysis and candidate markers}

Number of SEMs has been calculated for all samples. We identified 109,174 and 14,315 different SEMs in HCC tumor and adjacent non-tumor tissues, respectively. Among them 101,921 SEMs resulted present only in $\mathrm{HCC}$ and absent in adjacent non-cancerous tissues. We annotated genomic position of SEMs discovered in each sample and selected SEMs that were present in more than $90 \%$ of HCC samples and never present in adjacent non- cancerous tissues. Through this procedure a list of 4 genes (Table 3) was identified: Adherens Junctions Associated Protein 1 (AJAP1), Adenosine Deaminase RNA Specific B2 (ADARB2), Protein Tyrosine Phosphatase Receptor Type N2 (PTPRN2) and Sidekick Cell Adhesion Molecule 1 (SDK1).

\section{DISCUSSION}

DNA methylation is the main epigenetic mechanism adopted by cells to regulate gene expression, and alterations of this mechanism are involved in the pathogenesis of cancer. In this paper, we studied DNA methylation aberrations in HCC through the Illumina 450K DNA methylation array and adopting an innovative analysis devoted to the identification of epimutations.

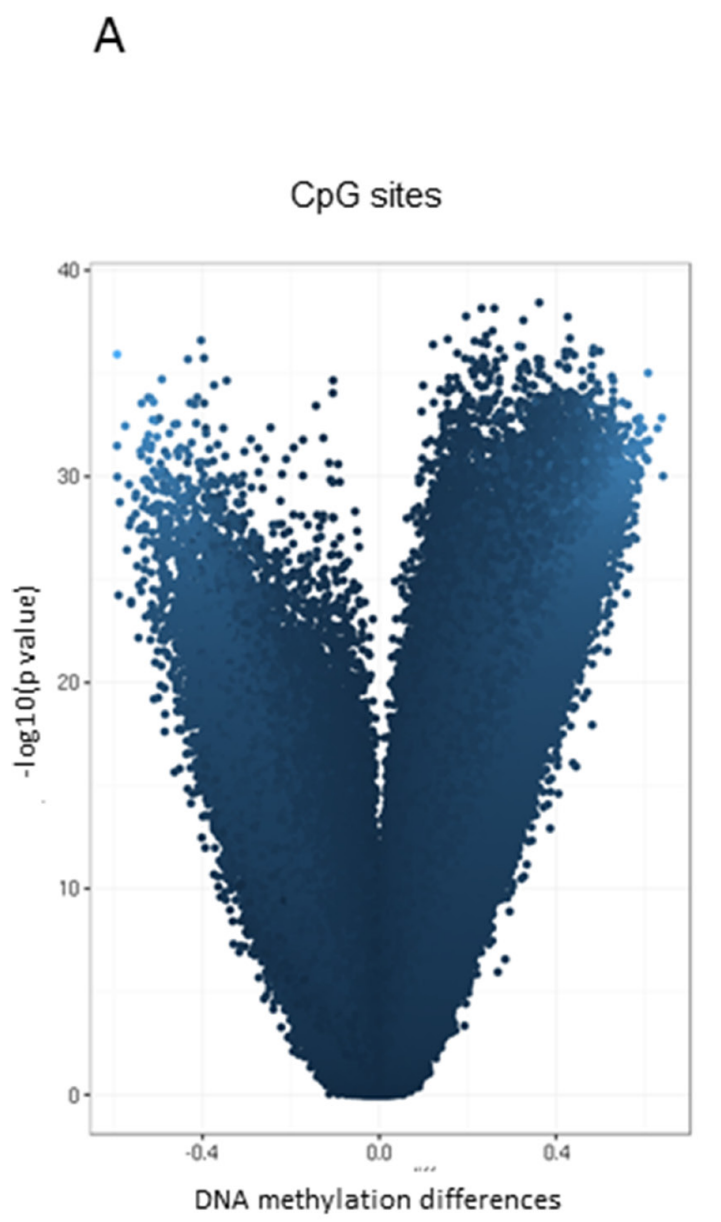

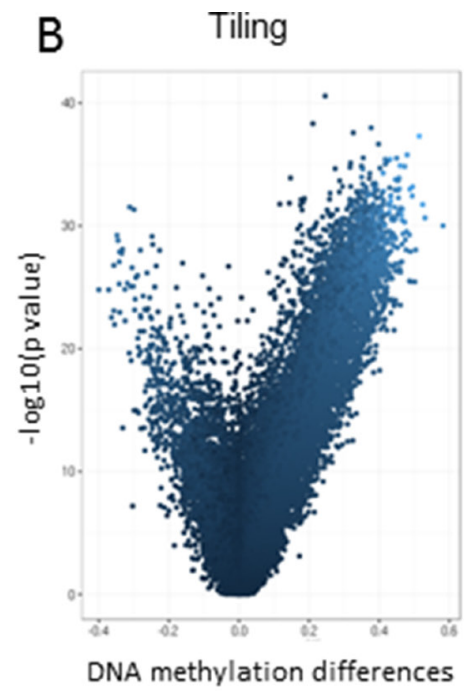

Promoters

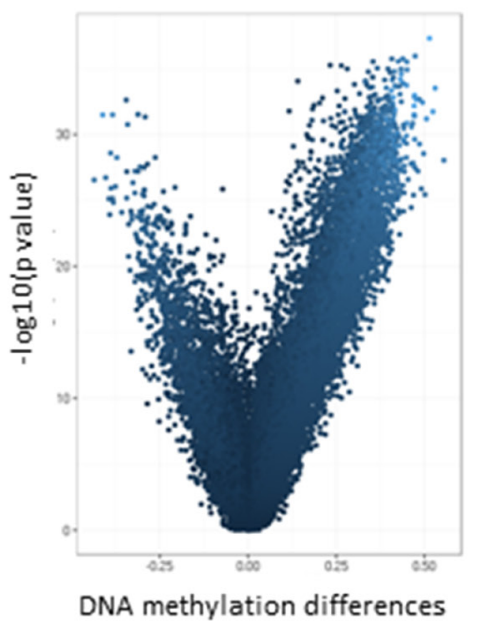

Genes

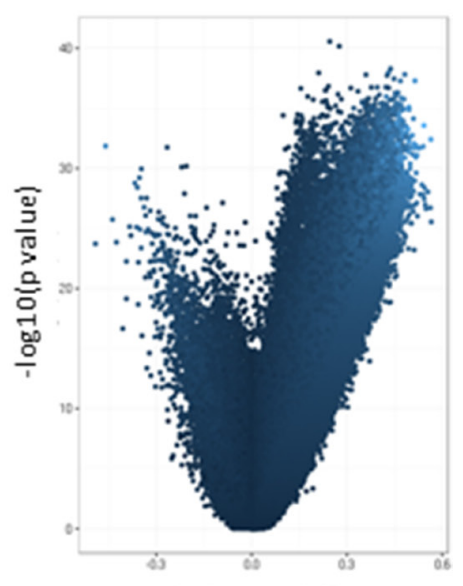

DNA methylation differences

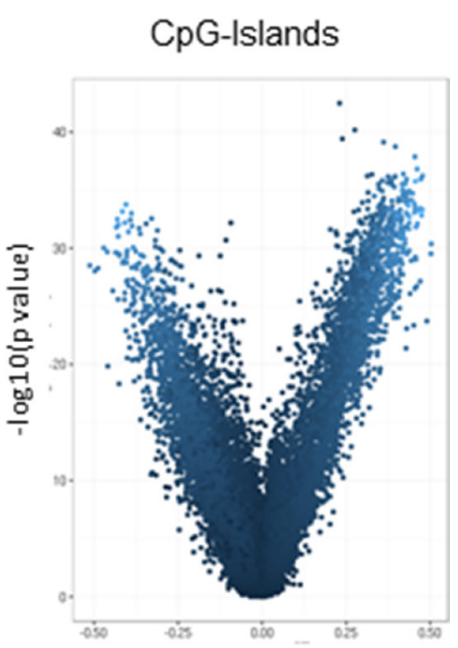

DNA methylation differences

Figure 3: Differential methylation analysis of Illumina 450K data. Volcano plot showing differential methylation analysis of 69 paired HCC tumor and adjacent non-cancerous liver tissues at site level (A) and at regional level (B). The x-axis represents the mean DNA methylation difference (adjacent non-cancerous liver tissue - HCC), while the y-axis shows the $-\log 10$ of the $p$ value for each CpG site $(\mathrm{A})$ or genomic region $(\mathrm{B})$. 
We characterized DNA methylation profiles in paired HCC tumor and adjacent non-cancerous liver tissue samples from 69 patients. Visual inspection of DNA methylation levels, obtained through multi-dimensional scaling, revealed a marked difference between HCC tumor and peritumoral tissues. Also the differential methylation analysis confirmed substantial changes of DNA methylation mainly due to loss of methylation in HCC.

Nishida et al. [17] compared DNA-methylation profile extracted from $59 \mathrm{HCC}$ with that from 58 adjacent non-cancerous liver tissues, using HumanMethylation 450 BeadChip array. They identified 38,330 CpG sites differentially methylated with an effect greater than $15 \%$ between both groups of samples, of which $92 \%$ and $8 \%$ were respectively hypomethylated (mainly located within intergenic regions) and hypermethylated (predominantly observed within promoter regions and $\mathrm{CpG}$ islands) in HCC. A significant association between methylation profile and tumor size has been detected, particularly in HCV-positive patients. A predominant DNA hypomethylation in $\mathrm{HCC}$ has been also reported by several other studies and a specific subset of $\mathrm{CpG}$ sites correlated with $\mathrm{HCV}$ infection and liver cirrhosis [10-13] .

In the present study we confirmed that $\mathrm{HCC}$ and adjacent non-cancerous tissues have a different epigenetic profile, indeed the number of differentially methylated probes resulted extremely high $(n=302,133)$. In this condition it is difficult to identify candidate epigenetic signatures and to highlight specific biological pathways and functions, considering that epigenetic deregulation is widespread throughout the genome. Several studies selected the top hypermethylated or hypomethylated genes on the basis of $p$ value or effect size [10-13]. However it has to be considered that the identification of best associations, based only on deserving of statistical thresholds, may lead to inconclusive or biased results.

On reviewing the literature, we identified four studies [10-13] that explored genome-wide DNA methylation profiles in HCC tumor and adjacent non-tumor tissues through Illumina's $450 \mathrm{~K}$ or $27 \mathrm{~K}$ arrays and published a list of the top differentially methylated $\mathrm{CpG}$ sites. A total number of 161 probes resulted combining the lists from these four studies (Supplementary Table 1). Although, all these probes have been confirmed in the present study with a similar trend, only 8 probes have been reported by at least 2 out of 4 selected studies. This poor overlap suggests that the selection of candidate markers obtained by fixing arbitrary statistical thresholds might produce biased results.

In our study, we used an alternative approach to identify epigenetic markers, based on epigenetic mutations analysis, as previously applied in the field of aging [15]. In each sample, SEMs have been identified using normal

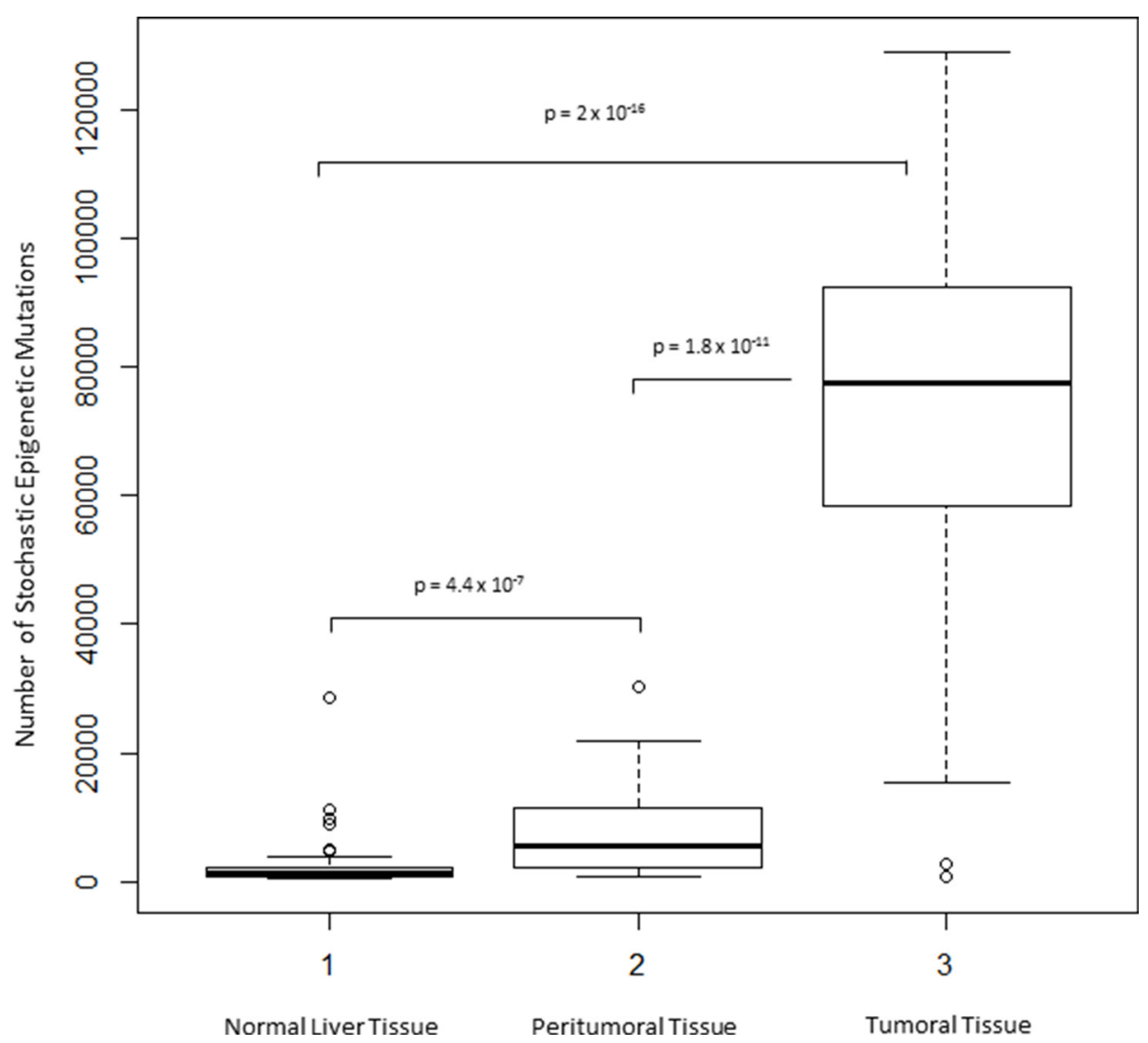

Figure 4: Exploration of SEMs in HCC. Box Plots show distribution of SEMs number in normal, peritumoral and HCC tumor tissues. 
Table 3: List of genes epimutated in more than $90 \%$ of HCC samples and never found in peritumoral tissues

\begin{tabular}{|c|c|c|c|c|c|c|c|c|c|c|}
\hline $\begin{array}{l}\text { Gene } \\
\text { Symbol }\end{array}$ & Ensemble_ID & Chr & Start & End & $\begin{array}{l}\text { Promoter Mean } \\
\text { Methylation } \\
\text { Level Normal } \\
\text { Liver Tissue }\end{array}$ & $\begin{array}{l}\text { Promoter Mean } \\
\text { Methylation } \\
\text { Peritumoral Tissue }\end{array}$ & $\begin{array}{l}\text { Promoter Mean } \\
\text { Methylation Level } \\
\text { Tumoral Tissue }\end{array}$ & $\begin{array}{l}\text { Gene Body Mean } \\
\text { Methylation } \\
\text { Level Normal } \\
\text { Liver Tissue }\end{array}$ & $\begin{array}{l}\text { Gene Body Mean } \\
\text { Methylation Level } \\
\text { Peritumoral Tissue }\end{array}$ & $\begin{array}{l}\text { Gene Body Mean } \\
\text { Methylation } \\
\text { Level Tumoral } \\
\text { Tissue }\end{array}$ \\
\hline AJAP1 & ENSG00000196581 & chr1 & 4714792 & 4852594 & 0.12 & 0.11 & 0.28 & 0.6 & 0.65 & 0.37 \\
\hline ADARB2 & ENSG000000185736 & $\operatorname{chr} 10$ & 1228073 & 1779670 & 0.08 & 0.08 & 0.12 & 0.72 & 0.75 & 0.41 \\
\hline PTPRN2 & \begin{tabular}{|l|l} 
ENSG00000155093 \\
\end{tabular} & chr7 & 157331750 & 158380480 & 0.25 & 0.28 & 0.45 & 0.8 & 0.77 & 0.43 \\
\hline SDK1 & ENSG00000146555 & $\operatorname{chr} 7$ & 3341080 & 4308632 & 0.12 & 0.1 & 0.36 & 0.85 & 0.81 & 0.49 \\
\hline
\end{tabular}

liver tissue methylation data as reference population. We have previously reported that the number of SEMs increases exponentially with age, and for this reason all analyses have been adjusted, considering age as covariate. Interestingly, we observed a progressive increase in the number of SEMs from normal liver, peritumoral tissue (predominantly with chronic hepatitis/cirrhosis) to HCC tissue. In HCC the median number of SEMs resulted 13 times higher than in adjacent non-cancerous liver tissue. Moreover the number of SEMs observed in peritumoral tissues was 4-fold higher than that identified in normal liver tissues obtained from healthy subjects. The number of SEMs observed in peritumoral and tumoral tissues resulted also significantly higher in samples with HBV and $\mathrm{HCV}$ viral infection. Both $\mathrm{HBV}$ and $\mathrm{HCV}$ infections have a main role in the development of HCC through genetic and epigenetic alterations. It has been reported that aberrant DNA methylation may be induced by direct viral activity or indirectly through related chronic liver inflammation [18]. In addition, it is well known that viral infection is able to affect DNA methyl transferase expression in HCC [19].

We also focused the attention on other clinicalphenotypic traits and we observed that the number of
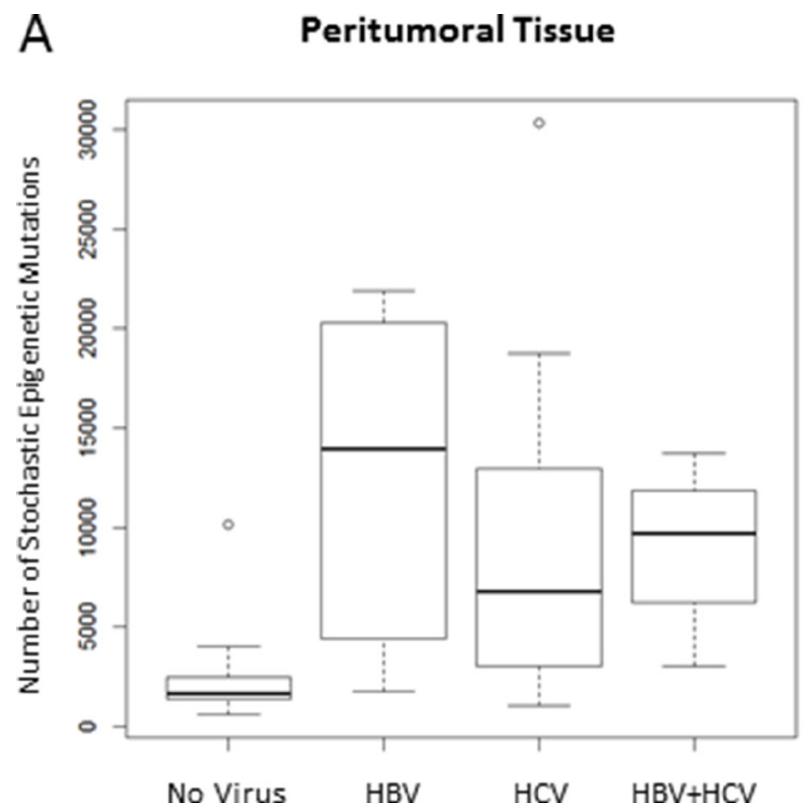

SEMs detected in HCC tissue increased progressively with histopathological tumor grade, suggesting that tumor progression and aggressiveness correlate with the accumulation of epigenetic alterations. This represents an interesting finding, supporting the potential use of SEMs number as a prognostic marker in HCC.

Therefore, the extreme heterogeneity and complexity among HCC epigenomes makes difficult to identify specific epigenetic profiles associated to phenotypic traits. While, the number of SEMs emerged as a new variable with high sensitivity and potentially able to summarize the degree of epigenetic alterations with a simple score.

In order to identify novel candidate potential epidrivers, after the calculation of SEMs, we analysed genomic position of SEMs discovered in each sample. We performed this analysis both for HCC and peritumoral tissues. We identified a list of SEMs that were present in more than $90 \%$ of HCC samples and never present in peritumoral tissues. Four genes emerged from this analysis: AJAP1, ADARB2, PTPRN2, SDK1. These epimutations were characterized by hypermethylation at promoters level and concomitant hypomethylation at gene body level in HCC tumor tissues (Table 3). Interestingly, a similar epigenetic signature for AJAP1, ADARB2 and

B

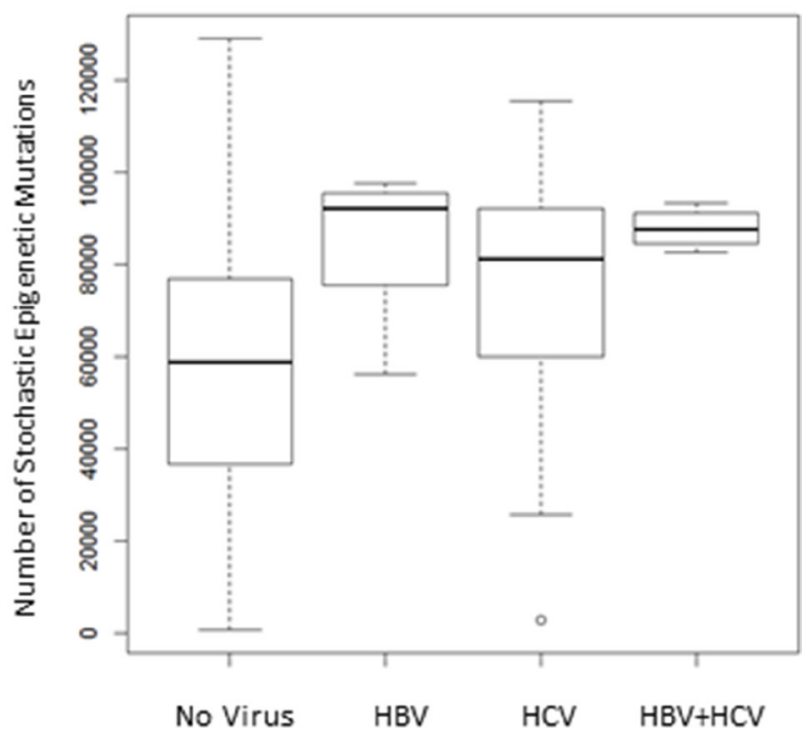

Figure 5: Number of SEMs is associated to viral infection. Box Plots show distribution of SEMs in peritumoral tissue (A) and $\mathrm{HCC}$ tumor tissue $(\mathbf{B})$ in relation to the $\mathrm{HBV} / \mathrm{HCV}$ infection status. 
PTPRN2 has been previously reported in glioblastoma [20-21]. Unfortunately, it was not possible using microarray-based method to understand if these epigenetic alterations were allele-specific.

AJAP1 is a component of adherent junctions. It interacts with E-cadherin- $\beta$-catenin complexes in polarized epithelial cells. The methylation of AJAP1 may lead to the release of $\beta$-catenin and the activation of Wnt signaling [22]. AJAP1 expression has been recently reported to be reduced in HCC compared with non-cancerous liver tissues and to be associated with hypermethylation of the AJAP1 promoter. Indeed, suppression of AJAP1 expression may represent a specific event that occurs in the final stage of the initiation of $\mathrm{HCC}$ [23]. Several evidences concerning the role of AJAP1 as a putative tumor suppressor genes regulated by promoter hypermethylation have been reported in cervical cancer, esophageal squamous cell carcinoma and gastric cancer $[22,24,25]$. In addition, it has been shown that AJAP1 expression was drastically reduced in glioblastoma tumors, and the loss of expression correlated with AJAP1 promoter hypermethylation and poorer survival. Interestingly, restoration of AJAP1 gene expression by transfection or demethylating agents decreased tumor cell proliferation and migration in glioblastoma cell lines [26].
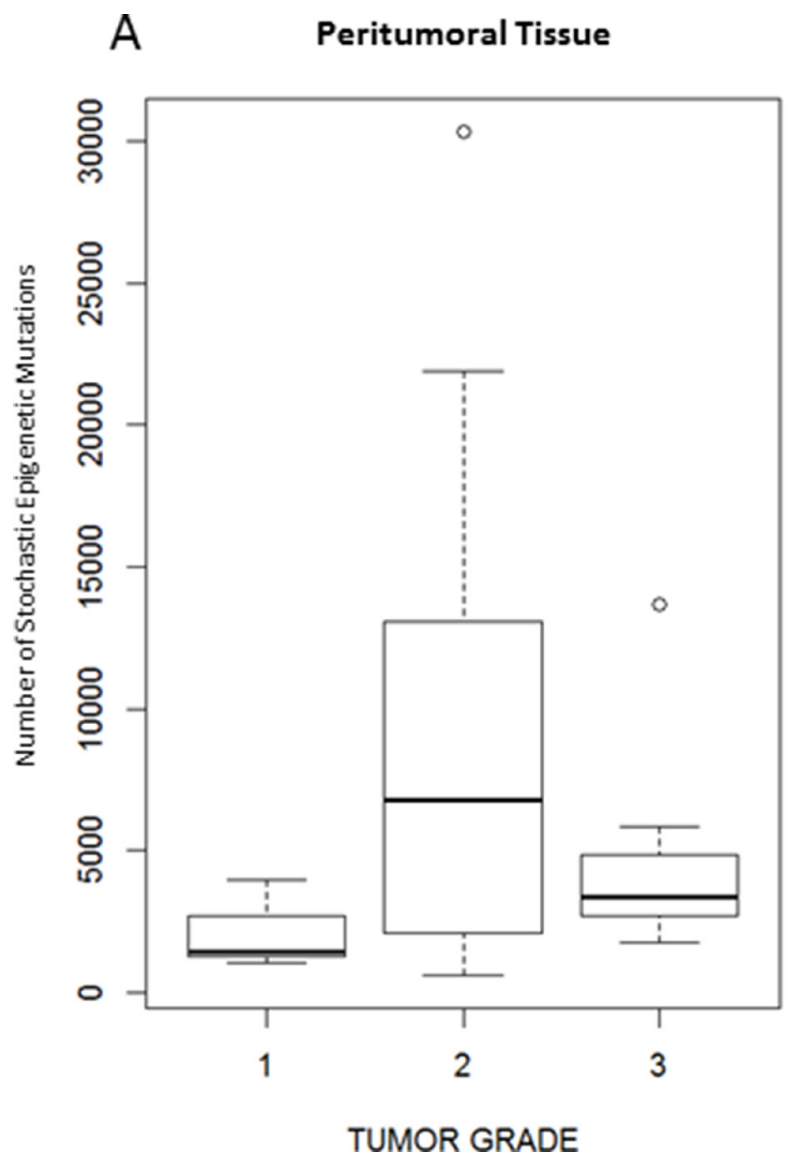

ADARB2 encodes a member of the double-stranded RNA adenosine deaminase family of RNA-editing enzymes and plays a regulatory role in RNA editing. This may affect gene expression and function through the modulation of: mRNA translation, by changing codons and hence the amino acid sequence of proteins; pre-mRNA splicing, by altering splice site recognition sequences; RNA stability, by changing sequences involved in nuclease recognition; genetic stability in the case of RNA virus genomes, by changing sequences during viral RNA replication; and RNA structure-dependent activities, such as microRNA production or targeting or protein-RNA interactions [21]. The gene body region of ADARB2 resulted extremely hypomethylated in $\mathrm{HCC}$ tumor compared to adjacent tissues. Currently there are no data available concerning the potential role of ADARB2 in the development of HCC. However, a growing body of evidence indicates an important role of adenosine to inosine RNA editing, modulated through epigenetic mechanisms, in the pathogenesis and progression of cancer [21, 27]: 1) hypomethylation of ADARB2 has been reported as a marker of relapse in pediatric acute lymphoblastic leukemia; 2) RNA levels of the three ADAR family members (ADAR, ADARB1, and ADARB2) were significantly reduced in brain tumors, the reduction of ADARB2 correlated with

\section{B HCC Tumor Tissue}

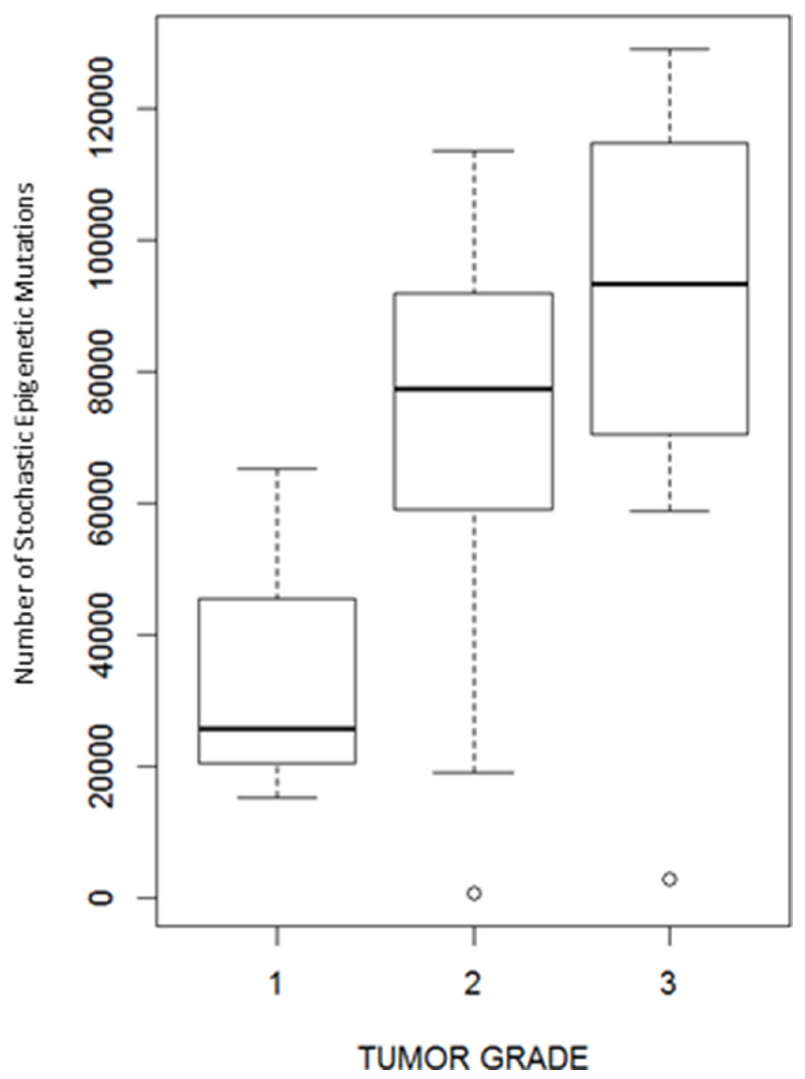

Figure 6: Number of SEMs is associated to tumor grade. Box Plots showing distribution of SEMs in peritumoral tissue (A) and tumoral tissue $(\mathbf{B})$ in relation to the tumor grade. 
the grade of malignancy of glioblastoma multiforme, the most aggressive of brain tumors, displaying a $99 \%$ decrease in ADARB2 RNA levels; 3) overexpression of ADAR and ADARB1 (an important paralog of ADARB2) in the U87 glioblastoma multiforme cell line significantly decreased proliferation rate.

PTPRN2 belongs to the protein tyrosine phosphatase family, it has an important role in vesicle-mediated secretory processes and exhibits a phosphatidylinositol phosphatase against phosphatidylinositol 4,5-diphosphate and phosphatidylinositol 3-phosphate [28]. PTPRN2 has been reported to be significant hypermethylated in squamous cell lung cancer and glioblastoma $[20,29]$. PTPRN2 resulted in the top list of marker down methylated in HCC, as reported by Shen et al [10], and similarly to our results the hypomethylation of this gene was restricted to the gene body region.

SDK1 gene codes for a cell adhesion molecule with a potential role in cancer progression. This gene is responsive to androgens, resulted overexpressed and able to regulate cellular migration in prostate cancer [30]. Moreover, in whole-exome sequencing studies performed on adrenocortical carcinoma, this gene was affected by somatic mutations [31]. However, to the best of our knowledge there are not data regarding the role of this gene in the pathogenesis of HCC.

In summary, we confirmed that HCC showed a methylation profile completely deregulated and very far from adjacent non-cancerous liver tissues. An alternative genome-wide DNA methylation analytical approach, based on the identification of epimutations, represents the real novelty of this study. This statistical approach resulted a robust method to appreciate epigenetic variability among samples. Indeed, the number of SEMs observed in HCC tissue was strongly associated to several important phenotypic traits. In addition, this analysis allowed the identification of four epigenetically regulated candidate genes (AJAP1, ADARB2, PTPRN2, SDK1), potentially involved in the hepatocarcinogenesis. Future studies are required to further validate the differential expression of these genes at the RNA or protein level in HCC.

\section{MATERIALS AND METHODS}

\section{Samples, patients and phenotypes}

Paired HCC tumor and adjacent non-cancerous liver tissue samples were obtained from 69 patients ( 16 females, 53 males) who underwent surgical resection from 2008 to 2015 at the National Cancer Institute of Naples. Samples were frozen immediately after surgical removal and stored at $-80^{\circ} \mathrm{C}$ until DNA extraction. Demographic data (age and gender), information on viral infection (HBV and HCV), clinical and pathological characteristics (alcoholic liver disease, non-alcoholic steatohepatitis, cirrhosis, ChildPugh class, tumor grade and tumor number) were obtained from the medical records. Written informed consent was obtained from all patients. This study was approved by the Ethics Committee of the Istituto Auxologico Italiano.

\section{DNA preparation and infinium methylation $450 \mathrm{~K}$ assay}

DNA was extracted using the QIAamp DNA Mini kit (Qiagen GmbH,D-40724 Hilden, Germany), according to the manufacturer's instructions. Bisulfite modification of $1 \mu \mathrm{g}$ DNA was conducted using an EZ DNA Methylation Kit (Zymo Research) according to the manufacturer's procedure. The Infinium Methylation $450 \mathrm{~K}$ assay was performed according to Illumina's standard protocol. Six HCC/adjacent non-tumor tissue pairs were processed on the same chip to avoid chip-tochip variation. Quality control and quantification of DNA were performed before and after bisulfite conversion.

\section{0k methylation data and populations description}

Methylation data analysed in the study were obtained from different datasets: 1 . The Case Population: 69 HCC tumor tissues. 2. The Control Population: 69 paired adjacent non-cancerous liver tissue samples. 3 . The Reference Population: Methylation raw data from 47 liver biopsies from healthy heart-beating and brain death donors with an age spanning from 13 to 90 years [32] were obtained from the Istituto Auxologico Italiano Epigenetic Database. Donors were free from known viral hepatitis and liver cirrhosis. Methylation row data from 67 normal liver tissues were obtained from the public functional genomics data repository GEO. We selected one dataset containing methylation idat files classified as normal liver tissue (GSE61446). Using these two datasets we obtained a unique reference containing 114 subjects. This population represented the reference population used for the estimation of epigenetic mutations.

\section{Data management, pre-processing, normalisation and quality control}

Illumina Methylation $450 \mathrm{~K}$ raw data were analysed using the RnBeads analysis software package [29]. Sites overlapping SNPs were firstly removed from the analysis $(n=4713)$ as well as probes on sex chromosomes $(n=11119)$. Probes and samples of highest impurity were removed from the dataset using the Greedycut algorithm provided in the RnBeads package. We have considered every $\beta$ value to be unreliable when its corresponding detection $p$-value was not below the threshold $(\mathrm{T}=0.05)$. The background was subtracted using the methylumi package (method "noob") [33]. The signal intensity values were normalized using the SWAN normalization method, as implemented in the minfi package. In addition 
to $\mathrm{CpG}$ sites, 4 sets of genomic regions were covered in the analysis (tailing, genes, promoters and $\mathrm{CpG}$ Islands).

\section{Differential methylation analysis and prioritization analysis}

Paired Differential methylation analysis was conducted both at site and region level according to the sample groups. $P$-values were computed using the limma method for the site level analysis, while a combined $p$-value was calculated from all site $p$-values for the region-based analysis [33]. After this analysis results have been ordered depending on their relevance on HCC field. Lists of hypermethylated and hypomethylated genes have been prioritized using the Phenolyzer on line tool (http:// phenolyzer.wglab.org/) and using "HEPATOCELLULAR CARCINOMA" and "HEPATIC" as key word.

\section{Epimutation detection}

In both HCC and adjacent liver tissue samples SEMs were identified, as previously described [15]. Briefly, after the pre-processing step, for all probes, the distribution and variability of methylation levels were studied using box and whiskers plots. Methylation levels of each sample were compared to those of normal liver tissues from a reference population. The same approach was applied also for each subject of the reference population. One by one each subject of the reference population was extracted and compared to the remaining N-1 subjects. At each locus, whenever the methylation level of one sample differed extremely from the rest of the population this outlier was considered as epimutated. Thus, for each locus, epimutated samples were identified as the extreme outliers when their methylation levels lay outside of Q1-(3 x IQR) and Q3+(3 x IQR). Finally, all epimutated loci were annotated in a new data matrix that allowed to calculate, for each sample, the total amount of epimutations and their genomic position. The box and whiskers plot analysis was conducted using boxplot function in the $\mathrm{R}$ car package and confirmed using the outlier function in the $\mathrm{R}$ outliers package. A validation of this analytical approach has been previously reported [15].

\section{Statistical analysis}

The "Shapiro.test" function provided in the R package "stats" was applied to test normality among variables. The "Wilcox.test" function provided in the R package "class" was used to test differences between cases and controls groups for all non-parametric data. Considering the presence of categorical variables, the Multiple Factor Analysis was performed using the Multiple Factor Analysis of mixt data approach and the "FAMD" function provided in the $\mathrm{R}$ package "FactoMineR". The univariate and multivariate linear regressions were conducted using the "Generalised Linear Model" function provided in the R “base” package. Bonferroni's correction was performed to correct for multiple testing.

\section{Abbreviations}

HBV: hepatitis B virus; HCC: hepatocellular carcinoma; HCV: hepatitis $\mathrm{C}$ virus; IQR: Interquartile range; MDS: Multi Dimensional Scaling SEMs: stochastic epigenetic mutations.

\section{Authors' contributions}

Gentilini D: contributed to acquisition of data, analysis and interpretation of data, drafting of the article and revising it for important contents and final approval of the version to be published. Vitale G: contributed to the conception and design of the study, acquisition of data, analysis and interpretation of data; drafting of the article and revising it for important contents and final approval of the version to be published. Franceschi C: contributed to acquisition of data and revising the article for important contents.Dicitore A: contributed to acquisition of data. Stefania S: contributed to acquisition of data. Gaudenzi G: contributed to acquisition of data. Garagnani P: contributed to acquisition of data and interpretation of data. Bacalini MG: contributed to acquisition of data and interpretation of data. Di Blasio AM: revising the article for important contents. Persani L: provided support and supervision of the study group and critical revision of the article. Capri M: contributed to acquisition of data. Cescon M: contributed to acquisition of data. Grazi GL: contributed to acquisition of data. Pisoni S: contributed to acquisition of data. Cirelli L: contributed to acquisition of data. Santagata S: contributed to acquisition of data. Izzo F: contributed to acquisition of data. All the authors approved the final version of the article.

\section{CONFLICTS OF INTEREST}

All authors disclosed no potential conflicts.

\section{FUNDING}

This study was funded by the Italian Ministry of Education, University and Research (grant number: FIRB RBAP11884 M) to GV and FI. The study was also partially supported by funds of the Ricerca Corrente of Istituto Auxologico Italiano, Milan, Italy (code: 05C205_2012) to GV and PRIN2008 to GLG (grant number: 2008WRBYPE).

\section{REFERENCES}

1. Torre LA, Siegel RL, Ward EM, Jemal A. Global Cancer Incidence and Mortality Rates and Trends-An Update. Cancer Epidemiol Biomarkers Prev. 2016; 25:16-27. doi: 10.1158/1055-9965.EPI-15-0578. 
2. Prete SD, Montella L, Caraglia M, Maiorino L, Cennamo G, Montesarchio V, Piai G, Febbraro A, Tarantino L, Capasso E, Palmieri G, Guarrasi R, Bianco M, et al. Sorafenib plus octreotide is an effective and safe treatment in advanced hepatocellular carcinoma: multicenter phase II So.LAR. study. Cancer Chemother Pharmacol. 2010; 66:837-44. doi: 10.1007/s00280-009-1226-Z.

3. Marra M, Sordelli IM, Lombardi A, Lamberti M, Tarantino L, Giudice A, Stiuso P, Abbruzzese A, Sperlongano R, Accardo M, Agresti M, Caraglia M, Sperlongano P. Molecular targets and oxidative stress biomarkers in hepatocellular carcinoma: an overview. J Transl Med. 2011; 9:171. doi: 10.1186/1479-5876-9-171.

4. Potenza N, Mosca N, Zappavigna S, Castiello F, Panella M, Ferri C, Vanacore D, Giordano A, Stiuso P, Caraglia M, Russo A. MicroRNA-125a-5p Is a Downstream Effector of Sorafenib in Its Antiproliferative Activity Toward Human Hepatocellular Carcinoma Cells. J Cell Physiol. 2017; 232:1907-13. doi: 10.1002/jcp.25744.

5. Stiuso P, Potenza N, Lombardi A, Ferrandino I, Monaco A, Zappavigna S, Vanacore D, Mosca N, Castiello F, Porto S, Addeo R, Prete SD, De Vita F, et al. MicroRNA-423-5p Promotes Autophagy in Cancer Cells and Is Increased in Serum From Hepatocarcinoma Patients Treated With Sorafenib. Mol Ther Nucleic Acids. 2015; 4:e233. doi: 10.1038/mtna.2015.8.

6. Huang Q, Lin B, Liu H, Ma X, Mo F, Yu W, Li L, Li H, Tian T, Wu D, Shen F, Xing J, Chen ZN. RNA-Seq analyses generate comprehensive transcriptomic landscape and reveal complex transcript patterns in hepatocellular carcinoma. PLoS One. 2011; 6:e26168. doi: 10.1371/ journal.pone.0026168.

7. Inokawa $\mathrm{Y}$, Inaoka $\mathrm{K}$, Sonohara F, Hayashi M, Kanda M, Nomoto S. Molecular alterations in the carcinogenesis and progression of hepatocellular carcinoma: Tumor factors and background liver factors. Oncol Lett. 2016; 12:3662-8. doi: 10.3892/ol.2016.5141.

8. Schulze K, Imbeaud S, Letouze E, Alexandrov LB, Calderaro J, Rebouissou S, Couchy G, Meiller C, Shinde J, Soysouvanh F, Calatayud AL, Pinyol R, Pelletier L, et al. Exome sequencing of hepatocellular carcinomas identifies new mutational signatures and potential therapeutic targets. Nat Genet. 2015; 47:505-11. doi: 10.1038/ng.3252.

9. Dhanasekaran R, Bandoh S, Roberts LR. Molecular pathogenesis of hepatocellular carcinoma and impact of therapeutic advances. F1000Res. 2016; 5. doi: 10.12688/ f1000research.6946.1.

10. Neumann O, Kesselmeier M, Geffers R, Pellegrino R, Radlwimmer B, Hoffmann K, Ehemann V, Schemmer P, Schirmacher P, Lorenzo Bermejo J, Longerich $\mathrm{T}$. Methylome analysis and integrative profiling of human HCCs identify novel protumorigenic factors. Hepatology. 2012; 56:1817-27. doi: 10.1002/hep.25870.

11. Shen J, Wang S, Zhang YJ, Kappil M, Wu HC, Kibriya MG, Wang Q, Jasmine F, Ahsan H, Lee PH, Yu MW, Chen CJ,
Santella RM. Genome-wide DNA methylation profiles in hepatocellular carcinoma. Hepatology. 2012; 55:1799-808. doi: 10.1002/hep.25569.

12. Shen J, Wang S, Zhang YJ, Wu HC, Kibriya MG, Jasmine F, Ahsan H, Wu DP, Siegel AB, Remotti H, Santella RM. Exploring genome-wide DNA methylation profiles altered in hepatocellular carcinoma using Infinium HumanMethylation 450 BeadChips. Epigenetics. 2013; 8:34-43. doi: 10.4161/epi.23062.

13. Song MA, Tiirikainen M, Kwee S, Okimoto G, Yu H, Wong LL. Elucidating the landscape of aberrant DNA methylation in hepatocellular carcinoma. PLoS One. 2013; 8:e55761. doi: 10.1371/journal.pone.0055761.

14. Zhang C, Li J, Huang T, Duan S, Dai D, Jiang D, Sui X, Li D, Chen Y, Ding F, Huang C, Chen G, Wang K. Metaanalysis of DNA methylation biomarkers in hepatocellular carcinoma. Oncotarget. 2016; 7:81255-67. doi: 10.18632/ oncotarget.13221.

15. Gentilini D, Garagnani P, Pisoni S, Bacalini MG, Calzari L, Mari D, Vitale G, Franceschi C, Di Blasio AM. Stochastic epigenetic mutations (DNA methylation) increase exponentially in human aging and correlate with $\mathrm{X}$ chromosome inactivation skewing in females. Aging (Albany NY). 2015; 7:568-78. doi: 10.18632/aging.100792.

16. Oey H, Whitelaw E. On the meaning of the word 'epimutation'. Trends Genet. 2014; 30:519-20. doi: 10.1016/j.tig.2014.08.005.

17. Nishida N, Nishimura T, Nakai T, Chishina H, Arizumi T, Takita M, Kitai S, Yada N, Hagiwara S, Inoue T, Minami Y, Ueshima K, Sakurai T, et al. Genome-wide profiling of DNA methylation and tumor progression in human hepatocellular carcinoma. Dig Dis. 2014; 32:658-63. doi: 10.1159/000367982.

18. Hattori N, Ushijima T. Epigenetic impact of infection on carcinogenesis: mechanisms and applications. Genome Med. 2016; 8:10. doi: 10.1186/s13073-016-0267-2.

19. Hlady RA, Tiedemann RL, Puszyk W, Zendejas I, Roberts LR, Choi JH, Liu C, Robertson KD. Epigenetic signatures of alcohol abuse and hepatitis infection during human hepatocarcinogenesis. Oncotarget. 2014; 5:9425-43. doi: 10.18632/oncotarget.2444.

20. Lee EJ, Rath P, Liu J, Ryu D, Pei L, Noonepalle SK, Shull AY, Feng Q, Litofsky NS, Miller DC, Anthony DC, Kirk MD, Laterra J, et al. Identification of Global DNA Methylation Signatures in Glioblastoma-Derived Cancer Stem Cells. J Genet Genomics. 2015; 42:355-71. doi: 10.1016/j.jgg.2015.06.003.

21. Paz N, Levanon EY, Amariglio N, Heimberger AB, Ram Z, Constantini S, Barbash ZS, Adamsky K, Safran M, Hirschberg A, Krupsky M, Ben-Dov I, Cazacu S, et al. Altered adenosine-to-inosine RNA editing in human cancer. Genome Res. 2007; 17:1586-95. doi: 10.1101/gr.6493107.

22. Chen YC, Huang RL, Huang YK, Liao YP, Su PH, Wang HC, Chang CC, Lin YW, Yu MH, Chu TY, Lai HC. Methylomics analysis identifies epigenetically silenced 
genes and implies an activation of beta-catenin signaling in cervical cancer. Int J Cancer. 2014; 135:117-27. doi: 10.1002/ijc.28658.

23. Ezaka K, Kanda M, Sugimoto H, Shimizu D, Oya H, Nomoto S, Sueoka S, Tanaka Y, Takami H, Hashimoto R, Okamura Y, Yamada S, Fujii T, et al. Reduced Expression of Adherens Junctions Associated Protein 1 Predicts Recurrence of Hepatocellular Carcinoma After Curative Hepatectomy. Ann Surg Oncol. 2015; 22:S1499-507. doi: 10.1245/s10434-015-4695-9.

24. Matsusaka K, Kaneda A, Nagae G, Ushiku T, Kikuchi Y, Hino R, Uozaki H, Seto Y, Takada K, Aburatani H, Fukayama M. Classification of Epstein-Barr viruspositive gastric cancers by definition of DNA methylation epigenotypes. Cancer Res. 2011; 71:7187-97. doi: 10.1158/0008-5472.CAN-11-1349.

25. Tanaka H, Kanda M, Koike M, Iwata N, Shimizu D, Ezaka K, Sueoka S, Tanaka Y, Takami H, Hashimoto R, Tanaka C, Yamada S, Fujii T, et al. Adherens junctions associated protein 1 serves as a predictor of recurrence of squamous cell carcinoma of the esophagus. Int J Oncol. 2015; 47:1811-8. doi: 10.3892/ijo.2015.3167.

26. Lin N, Di C, Bortoff K, Fu J, Truszkowski P, Killela P, Duncan C, McLendon R, Bigner D, Gregory S, Adamson DC. Deletion or epigenetic silencing of AJAP1 on 1p36 in glioblastoma. Mol Cancer Res. 2012; 10:208-17. doi: 10.1158/1541-7786.MCR-10-0109.

27. Nordlund J, Backlin CL, Wahlberg $\mathrm{P}$, Busche S, Berglund EC, Eloranta ML, Flaegstad T, Forestier E, Frost BM, Harila-Saari A, Heyman M, Jonsson OG, Larsson R, et al. Genome-wide signatures of differential DNA methylation in pediatric acute lymphoblastic leukemia. Genome Biol. 2013; 14:r105. doi: 10.1186/gb2013-14-9-r105.
28. Caromile LA, Oganesian A, Coats SA, Seifert RA, BowenPope DF. The neurosecretory vesicle protein phogrin functions as a phosphatidylinositol phosphatase to regulate insulin secretion. J Biol Chem. 2010; 285:10487-96. doi: 10.1074/jbc.M109.066563.

29. Anglim PP, Galler JS, Koss MN, Hagen JA, Turla S, Campan M, Weisenberger DJ, Laird PW, Siegmund KD, Laird-Offringa IA. Identification of a panel of sensitive and specific DNA methylation markers for squamous cell lung cancer. Mol Cancer. 2008; 7:62. doi: 10.1186/1476-4598-7-62.

30. Verone AR, Duncan K, Godoy A, Yadav N, Bakin A, Koochekpour S, Jin JP, Heemers HV. Androgen-responsive serum response factor target genes regulate prostate cancer cell migration. Carcinogenesis. 2013; 34:1737-46. doi: 10.1093/carcin/bgt126.

31. Juhlin CC, Goh G, Healy JM, Fonseca AL, Scholl UI, Stenman A, Kunstman JW, Brown TC, Overton JD, Mane SM, Nelson-Williams C, Backdahl M, Suttorp AC, et al. Whole-exome sequencing characterizes the landscape of somatic mutations and copy number alterations in adrenocortical carcinoma. J Clin Endocrinol Metab. 2015; 100:E493-502. doi: 10.1210/jc.2014-3282.

32. Capri M, Olivieri F, Lanzarini C, Remondini D, Borelli V, Lazzarini R, Graciotti L, Albertini MC, Bellavista E, Santoro A, Biondi F, Tagliafico E, Tenedini E, et al. Identification of miR-31-5p, miR-141-3p, miR-200c-3p, and GLT1 as human liver aging markers sensitive to donorrecipient age-mismatch in transplants. Aging Cell. 2017; 16:262-72. doi: 10.1111/acel.12549.

33. Assenov Y, Muller F, Lutsik P, Walter J, Lengauer T, Bock C. Comprehensive analysis of DNA methylation data with RnBeads. Nat Methods. 2014; 11:1138-40. doi: 10.1038/nmeth.3115. 